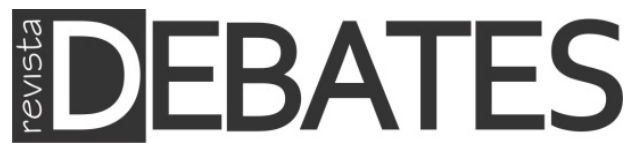

\title{
Como os partidos políticos brasileiros usam a Internet para atrair o eleitorado jovem
}

\author{
How Brazilian political parties use the Internet to attract young \\ voters
}

\section{Antonio Teixeira de Barros}

\section{Resumo}

Este artigo analisa como os 32 partidos políticos brasileiros usam a Internet para se comunicar com os segmentos jovens do eleitorado. O estudo identifica quatro estratégias de conexão com o eleitorado juvenil: (a) núcleo ou secretaria da juventude nos websites das agremiaçóes; (b) divulgaçáo de informaçóes e eventos de interesses da juventude; (c) oferta de cursos online de educaçáo política para jovens; (d) uso de redes sociais online. A visibilidade e a propaganda sobre os feitos partidários são os aspectos que se destacam, como tática para captar a atenção dos jovens eleitores.

\section{Palavras-chave}

Partidos Políticos; Comunicação Partidária; Juventude; Internet; Política Informacional.

\begin{abstract}
This paper analyzes how the Brazilian political parties use of the Internet to communicate with the young segment of the electorate. The study identifies four strategies to reach them: (a) through contact with the website of the youth department of the political parties, (b) the dissemination of information and events of interest to the youth, (c) the offering of online courses on political education, (d) the usage of online social networks. In order to reach this segment of the electorate it is important to show all the diferent parties' acomplishments.
\end{abstract}

\section{Keywords}

Political Parties; Party Communication; Internet; Informational Politics. 


\section{Introdução}

O objetivo deste artigo é analisar como os 32 partidos políticos brasileiros usam a Internet na atualidade para estabelecer formas de contato e relacionamento com o eleitorado jovem. O propósito é mapear como se dá o uso dessas estratégias e verificar se há perfis partidários diferenciados, em termos de relação com esse segmento eleitoral. $\mathrm{O}$ modo como os partidos se relacionam com seus públicos eleitorais e com entidades da sociedade civil que os representam é um dos eixos dos estudos atuais sobre a organizaçáo dos partidos, conforme registra Amaral (2013).

O estudo pretende contribuir para a compreensão de como as legendas tentam atrair a juventude para suas propostas políticas, considerando que as diversas agremiaçóes representam a pluralidade ideológica da política (PEIRANO, 2011). As diferentes agremiaçóes correspondem às distintas visões e divisóes do mercado político e dos movimentos de juventude; portanto, oferecem, no âmbito do sistema de representação democrático liberal, as possibilidades de adesão política aos eleitores jovens.

A metodologia consistiu no monitoramento e análise dos websites das legendas, com o propósito de mapear de que forma os partidos estabelecem suas estratégias de relação e de interação com os segmentos juvenis. O levantamento foi realizado no período de agosto a setembro de 2014, durante a campanha eleitoral para as eleições nacionais. Para tanto, foram consideradas as informaçôes disponíveis nos websites dos próprios partidos.

O período eleitoral é relevante por se tratar do momento em que, ao lançarem suas candidaturas, os partidos usam variadas estratégias para reforçar seu papel na mediação política e seu poder de palavra e de influência na esfera pública. Ficam em evidência, portanto, as estratégias de publicidade política, entendidas como uma forma de propaganda das legendas, a fim de consolidar seu poder de influência política. Essa, provavelmente, é uma das razóes que explicam a ampla adesão dos partidos às estratégias de relaçáo com o segmento juvenil.

\section{Partidos politicos, Internet e juventude}

Várias análises enfatizam a crise da mediação política nas sociedades contemporâneas, representada, em boa parte, pela crise dos próprios partidos, o que resultou na chamada desideologização partidária (PANEBIANCO, 1990). Outros autores ressaltam a baixa institucionalização partidária no Brasil, a fraca identificação com o eleitorado (CARREIRÃO e KINZO, 2004; VEIGA, 2007; AMARAL, 2013) e uma tendência geral na diminuição da importância dos partidos políticos 
(MAINWARING, 2001; BAQUERO, 2000; MANIN, 2013). Outros estudos, contudo, apontam para uma tendência de requalificação dos partidos, o que implica redefiniçóes, atualização e adaptação aos novos contextos. Isso não implicaria, portanto, enfraquecimento ou declínio das legendas, mas uma redefinição de suas funçóes e de seus modos de atuação e operação política (AMARAL, 2013).

Se a decadência dos sistemas partidários é consensual ou não na literatura, o fato é que as pesquisas realizadas nas últimas décadas no Brasil revelam um declínio na confiança do público em relação aos partidos (MOISÉS, 2005; MENEGUELLO, 2000) e também no nível de filiação ou estabilidade nas preferências partidárias (PEREIRA, 2014). Segundo Manin (2013), os partidos deixaram de ser sujeitos políticos com identidades definidas e passaram a ser apenas instrumentos dos eleitores, empregados a cada eleição, dependendo das circunstâncias políticas.

Por outro lado, pensadores políticos ressaltam que, apesar das redefiniçóes frequentes, frutos das crises e metamorfoses da democracia (URBINATI, 2013), os partidos políticos ainda conservam algumas características e funçôes que lhes são peculiares na esfera de pertinência da mediação política e das configuraçôes associativas (WEBER, 1999). Segundo Manin (2013), apesar de perderem força em várias áreas, os partidos continuam dominando a política parlamentar e as campanhas eleitorais em todos os países. Mesmo com a pluralidade de funçóes, interesses e desenhos institucionais, há um elemento que define por essência um partido político, ou seja, seu caráter de associação (WEBER, 1999), uma das causas de afirmação de seu poder. É por essa razão que, nos termos weberianos, o partido é, antes de tudo, uma associação no seio da comunidade política, independentemente de seus fins ou objetivos, dotada, por isso, de potencial de criação de capital social e político. Nesse ponto, é preciso ter em mente a complexa articulação entre identidade e instrumentalidade exercida pelos partidos, isto é, a relação paradoxal agenciada, ao combinarem valores e interesses no processo político (REIS, 2010).

A natureza da associaçáo realizada pelos partidos está intrinsecamente relacionada a uma formação que luta pela dominação, ou seja, o objetivo é assegurar um campo de exercício de influência e poder, seja pelos recursos econômicos obtidos, pela influência social ou pelo poder de palavra. Nesse último quesito, situam-se as estratégias de publicidade política, entendidas como uma forma de propaganda das legendas, a fim de consolidar seu poder discursivo e simbólico, nos termos de Bourdieu (1989). Funcionam como revitalizadores da mediação entre os cidadãos e as instituiçóes partidárias. Desse ponto de vista, os partidos servem como mediadores 
entre a sociedade e o Estado, uma vez que organizam os termos da competição eleitoral.

Analisados pragmaticamente, os partidos são instituiçóes que exercem as seguintes funçôes: a) do ponto de vista do eleitorado, simplificam as escolhas dos cidadãos, mobilizando-os para participar; b) do ponto de vista organizacional, ajudam a recrutar líderes; c) do ponto de vista governamental, participam da criação de maiorias, organizam o governo, principalmente no Legislativo, e organizam a oposição (DALTON e WATTEMBERG, 2000). Os objetivos podem ser a busca de votos (para cargos), posiçóes sobre políticas ou cargos no poder. Nesse quesito, Manin (2013) destaca que existe uma tendência de personalização política, pois as legendas contemporâneas fazem campanhas centradas nos candidatos e nas personalidades deles e dos líderes. Para o autor, as siglas conseguiram se adaptar à tendência impulsionada pelos meios de comunicaçáo de massa e, ainda que as eleiçóes tenham se tornado personalizadas, continuam partidárias.

A opção pela análise com base nos websites dos partidos se justifica pela crescente relevância do uso de ferramentas digitais pelos partidos políticos e demais instituiçóes políticas, conforme mostram vários estudos recentes (ALBUQUERUQE e MARTINS, 2010). A Internet, portanto, constitui uma ferramenta para otimizar a atuação dos partidos. Afinal, no contexto de uma sociedade de multirredes (BAUMAN, 2000), os partidos (e todas as demais instituiçôes políticas) deparam-se com a lógica da inevitabilidade digital, resultante do processo de encolhimento do mundo (HARVEY, 1992) e de constituição de novos modos do fazer político. A Internet renovou o campo político, com um novo tipo de copresença, por meio da atuação online dos atores. Ressalta-se, nesse aspecto, a capacidade de agência do usuário de Internet, com sua múltipla atuação (espectador, ator e operador). Os partidos tiveram que aderir, portanto, à politica de signos para criar e representar modos de pertencimento do cidadáo (RIBEIRO, 2000).

No regime de visibilidade da democracia de público, a política informacional (CASTELLS, 2003) torna-se cada vez mais imperativa. Afinal, a geração, o processamento e a transmissão de informaçóes e imagens tornaram-se as fontes fundamentais de produtividade de poder. Por isso, os partidos políticos tendem, cada vez mais, a recorrer a estratégias de sedução política pela Internet, cujos websites são o foco da divulgaçáo, uma espécie de "palanque virtual" ou de outdoor na esfera virtual (CASTELLS, 2003). Isso explica, ainda, porque os partidos "investem progressivamente em estratégias de promoçáo da personalidade e de democracia de contato". Além disso, "aderem aos recursos midiáticos para captar a atenção pública" 
(LIPOVETSKI, 2013, p. 50-51). É oportuno ressaltar que a literatura especializada mostra como a relação entre política Internet tornou-se inevitável, com o uso quase generalizado de websites pelos partidos políticos (ALBUQUERQUE e MARTINS, 2010; BLANCHARD, 2006; ROMMELE, 2003; LESTON-BANDEIRA 2012).

No caso da juventude, estudos empíricos apontam para uma multiplicidade de formas de engajamento político, as quais enveredam por caminhos diversos, sejam os da política institucional, sejam os da ação militante fora da esfera partidárias (CASTRO, 2008; MAYORGA, CASTRO e PRADO, 2012). Outra característica do engajamento político juvenil é que nem sempre o sentido político das ações aparece de forma ostensiva, ou seja, pode náo ser explicitado ou admitido pelos jovens. $\mathrm{O}$ engajamento juvenil, contudo, é impulsionado pelo idealismo (CASTRO, 2008), marcado pela convergência na defesa de causas comuns, independentemente da orientação ideológico-partidária. Essa convergência é expressa, por exemplo, no combate à corrupção política, na redução das desigualdades sociais e na reivindicação de melhores serviços públicos, especialmente educação, saúde e mobilidade urbana.

Os estudos supracitados destacam a suspeita dos jovens em relação à política institucionalizada. As disputas, os debates e conflitos característicos da esfera partidária, por exemplo, são vistos como impedimentos para o engajamento no plano institucional, pois implicam negociatas e acordos suspeitos. Tais arranjos sáo considerados instrumentos para a máquina partidária, algo que se distancia do ideal da transformação sociopolítica almejada. Por essa razão, os jovens preferem "uma via direta de ação e de participação na sociedade, em que podem constatar, por eles mesmos, os efeitos do que fazem, sem intermediaçóes" (CASTRO, 2008, p. 263). Dados da Pesquisa Nacional sobre o Perfil e a Opinião dos Jovens Brasileiros ${ }^{1}$ mostram que $54 \%$ deles nunca participaram de nenhuma atividade política no âmbito institucional e que $45 \%$ reconhecem as mobilizaçóes de rua, protestos, manifestaçóes e outras açôes diretas como a via mais indicada para a soluçáo de problemas sociais. Outros levantamentos mostram até $82 \%$ de desinteresse dos jovens pela política em suas modalidades institucionalizadas² (BAPTISTA et al., 2013). Outro levantamento mostra que 59\% dos jovens afirmam que o Brasil seria melhor se não houve partidos políticos (RODRIGUES, 2014).

\footnotetext{
1 Pesquisa realizada pela Secretaria Nacional da Juventude, em 2013. Disponível em: http://www.polis.org.br/uploads/1982/1982.pdf .

${ }^{2}$ Pesquisa Juventude, Participação e Voto, Universidade Federal de Minas Gerais, 2010. Disponível em: http://www.opiniaopublica.ufmg.br/pesquisas_detalhe.php?id=41.
} 
Os dados estão em consonância com as tendências indicadas pela literatura especializada, que registra um refluxo nas formas convencionais de engajamento político entre os jovens e um crescimento na adesão à contestaçáa e ao protesto (RIBEIRO, 2012). A rejeição às práticas políticas estabelecidas é nitidamente rechaçada pelos movimentos juvenis, levando-os a negar que fazem política, mesmo quando existem características tipicamente políticas (MAYORGA, CASTRO e PRADO, 2012; TELLES e DIAS, 2010). Isso implica a rejeição à política partidária.

Esse quadro se explica pela elevada desconfiança da juventude na política, em contraposição a um cenário de forte confiança na família, nas igrejas e nas entidades não governamentais (PAIVA, 2010). Os estudos mostram que a política "não parece interpelar os jovens como atividade criadora e transformadora do mundo" (CASTRO, 2009, p. 480). O fato é que, segundo a última autora citada, a política como o campo da diferença e da contradição requer um certo nível de competência cognitiva que nem sempre é possível da parte dos jovens. Além disso, há que se considerar ainda a relevância dos contextos privados de socialização política aos quais estão expostos os jovens desde sua infância.

Conforme aponta Okado (2013, há uma variedade de estudos empíricos que confirmam o diagnóstico de uma queda no engajamento político juvenil na política institucional. Uma das referências principais sobre o assunto é o estudo de Norris (2003). Para a autora, a análise do engajamento político juvenil deve considerar três ordens de efeitos. A primeira compreende os efeitos geracionais, que explicariam o maior ou menor interesse em política, de acordo com a faixa etária. A segunda abrange os "efeitos de ciclos de vida", ou seja, explica eventuais mudanças nos critérios e prioridades das escolhas políticas em função do ciclo de vida do cidadão. $\mathrm{O}$ terceiro abarca os "efeitos de período", isto é, como as preferências e escolhas variam em função da conjuntura política e econômica, o que requer análise comparada de diferentes períodos da vida do cidadáo e não apenas a fase juvenil.

Ao realizar estudo empírico no contexto brasileiro, com base no modelo proposto por Pipa Norris, Okado (2013) aponta duas perspectivas analíticas para este fenômeno. A primeira tem como base explicaçôes centradas na transição geracional, ou seja, o desinteresse dos jovens pela política institucionalizada seria decorrência de uma certa fase do ciclo de vida social, focado em determinadas prioridades valorativas dos jovens. A segunda abordagem tem como eixo explicativo os estudos sobre socialização política e sustenta a tese de que as diferenças notadas nos padrôes de engajamento político em faixas etárias estáo relacionadas com o aprendizado que se desenvolveu no seio da família e das relaçôes interpessoais. Assim, os repertórios 
"seriam construídos no decorrer da vida, marcados pelas trocas simbólicas e pelos processos de aquisição de competências cognitivas ao longo do desenvolvimento individual" (OKADO, 2013, p. 38).

A literatura internacional sobre comportamento político registra que a faixa etária é uma variável de grande relevância quando se trata de interesse por política e formas de participação, com base no argumento de "os recursos materiais e cognitivos relacionados a participação, bem como os vínculos sociais, se acumulam no decorrer do tempo" (OKADO, 2013, p. 41). Assim, o jovem se interessaria menos por política, mas, conforme adquire maiores níveis educacionais, amplia o seu interesse quando adulto e se desinteressa na terceira idade devido à reduçáo de seus vínculos sociais. Trata-se do que Milbrath e Goel (1977) denominam "efeito curvilíneo" entre interesse por política e idade.

O componente geracional, portanto, revela-se uma variável relevante no contexto recente. Por outro lado, o mesmo autor chama atenção para a necessidade de estudos empíricos que confirmem a tendência apontada no cenário brasileiro, uma vez que dados coletados a partir dos levantamentos do Latinobarômetro mostram que ainda temos percentuais e padrôes "muito semelhantes entre os estratos etários" (RIBEIRO, 2012, p. 30), diferentemente do que mostram estudos empíricos estrangeiros. Tal constatação leva ao questionamento acerca da emergência de uma cidadania mais crítica e contestatória entre os jovens brasileiros:

Apesar de pesquisadores apresentarem evidências consistentes sobre uma
mudança geracional no padrão de participação em algumas democracias
consolidadas (...), esse não é um fenômeno verificável entre o público
brasileiro, pelo menos até o momento coberto pelos dados disponíveis.
Comparando as frequências de comportamentos e algumas atitudes de
distintas faixas etárias do público nacional, não foram encontradas
diferenças importantes, o que nos leva à conclusão de que não podemos
falar de uma juventude mais crítica em relação às formas convencionais
de envolvimento ou mais engajada em modalidades ligadas ao protesto
político (RIBEIRO, 2012, p. 33).

Outra observação relevante sob a ótica geracional é o potencial de novidade e de criatividade que é inerente aos jovens, uma vez que eles "constituem-se enquanto novidade histórica" em relação às demais geraçôes e "às tradiçôes culturais que se pretendem hegemônicas, pois, enquanto nova geração, a juventude está fora da lógica estruturante do mundo já instituído” (ZITKOSKI e HAMMES, 2014, p. 136). 
Embora a juventude seja representada sociologicamente como "uma categoria relacional que posiciona os indivíduos como pertencente a uma dada faixa etária" (GOHN, 2013, p. 205), o que as pesquisas recentes mostram é que existem várias juventudes. Cada vez mais, os jovens passam a ser caracterizados como um grupo social plural e emergente (MALFITANO, 2011) ${ }^{3}$, com diferentes formas de engajamento, variados repertórios de ação coletiva e múltiplas agendas (DAYRELL, MOREIRA e STENGELl, 2011), o que requer olhares menos simplificadores. Isso dificulta a identificaçáo de um padrão de engajamento e de participação, além de apontar para a dificuldade de se registrar tendências uniformes e estanques (RIBEIRO, LANES e CARRANO, 2006).

Diante do exposto, cumpre-nos examinar como os websites dos partidos políticos brasileiros traçam suas estratégias de relação política com esse segmento do eleitorado, conforme será detalhado a seguir.

\section{Análise dos dados}

Foram consideradas quatro estratégias dos partidos para o relacionamento com a juventude, a partir de uma análise prévia dos websites. A primeira consiste na criação de um núcleo ou secretaria da juventude nos portais das agremiaçóes. A segunda compreende a divulgaçáo de informaçóes e eventos de interesses da juventude nos websites. A terceira contempla a oferta de cursos online de educação política para jovens. A quarta consiste no uso de redes sociais que, embora náo seja exclusivo da juventude, tem, nesse segmento, seu principal público. Alguns partidos aderem a apenas uma dessas estratégias, enquanto outros combinam mais de uma delas ou todas, conforme será detalhado na sequência. Os websites examinados constam no Quadro 1.

Quadro 1 - Partidos Políticos Registrados na Justiça Eleitoral

\begin{tabular}{|l|l|l|l|l|}
\hline & Sigla & Legenda & Registro & Website \\
\hline 1 & PMDB & $\begin{array}{l}\text { Partido do Movimento } \\
\text { Democrático Brasileiro }\end{array}$ & 30.6 .1981 & http://pmdb.org.br/ \\
\hline 2 & PTB & Partido Trabalhista Brasileiro & 3.11 .1981 & http://www.ptb.org.br/ \\
\hline 3 & PDT & Partido Democrático & 10.11 .1981 & $\mathrm{http} / /$ www.pdt.org.br/ \\
\hline
\end{tabular}

\footnotetext{
${ }^{3}$ Ao mesmo tempo em que impera essa visão plural da juventude sob a ótica sociocultural, a autora alerta que "observa-se uma uniformização da ideia de juventude, considerando-a indistintamente como um grupo único, para o qual se lança o olhar como 'problema político' necessitando de intervenção e de controle" (MALFITANO, 2011, p. 525).
} 


\begin{tabular}{|c|c|c|c|c|}
\hline & & Trabalhista & & \\
\hline 4 & $\mathrm{PT}$ & Partido dos Trabalhadores & 11.2 .1982 & http://www.pt.org.br/ \\
\hline 5 & DEM & Democratas & 11.9 .1986 & http://www.dem.org.br/ \\
\hline 6 & PCdoB & Partido Comunista do Brasil & 23.6 .1988 & http://www.pcdob.org.br/ \\
\hline 7 & PSB & Partido Socialista Brasileiro & $1^{\circ} .7 .1988$ & http://www.psb40.org.br/ \\
\hline 8 & PSDB & $\begin{array}{l}\text { Partido da Social Democracia } \\
\text { Brasileira }\end{array}$ & 24.8.1989 & http://www.psdb.org.br/ \\
\hline 9 & PTC & Partido Trabalhista Cristão & 22.2 .1990 & http://www.ptc36nacional.com.br/ \\
\hline 10 & PSC & Partido Social Cristão & 29.3 .1990 & http://www.psc.org.br/ \\
\hline 11 & PMN & $\begin{array}{l}\text { Partido da Mobilização } \\
\text { Nacional }\end{array}$ & 25.10 .1990 & http://pmn.org.br/ \\
\hline 12 & PRP & $\begin{array}{l}\text { Partido Republicano } \\
\text { Progressista }\end{array}$ & 29.10 .1991 & http://www.prp.org.br/ \\
\hline 13 & PPS & Partido Popular Socialista & 19.3 .1992 & http://portal.pps.org.br/ \\
\hline 14 & PV & Partido Verde & 30.9 .1993 & http://pv.org.br/ \\
\hline 15 & PTdoB & Partido Trabalhista do Brasil & 11.10 .1994 & http://www.ptdob.org.br/home/ \\
\hline 16 & $\mathrm{PP}$ & Partido Progressista & 16.11 .1995 & http://www.pp.org.br/ \\
\hline 17 & PSTU & $\begin{array}{l}\text { Partido Socialista dos } \\
\text { Trabalhadores Unificado }\end{array}$ & 19.12 .1995 & http://www.pstu.org.br/ \\
\hline 18 & PCB & Partido Comunista Brasileiro & 9.5 .1996 & http://pcb.org.br/portal/ \\
\hline 19 & PRTB & $\begin{array}{l}\text { Partido Renovador } \\
\text { Trabalhista Brasileiro }\end{array}$ & 28.3.1995 & http://prtb.org.br/ \\
\hline 20 & PHS & $\begin{array}{l}\text { Partido Humanista da } \\
\text { Solidariedade }\end{array}$ & 20.3.1997 & http://phs.org.br/ \\
\hline 21 & PSDC & $\begin{array}{l}\text { Partido Social Democrata } \\
\text { Cristão }\end{array}$ & 5.8 .1997 & http://www.psdc.org.br/ \\
\hline 22 & PCO & Partido da Causa Operária & 30.9 .1997 & http://www.pco.org.br/ \\
\hline 23 & PTN & Partido Trabalhista Nacional & 2.10 .1997 & http://www.ptn.org.br/2013/ \\
\hline 24 & PSL & Partido Social Liberal & 2.6 .1998 & http://www.psl.org.br/ \\
\hline 25 & PRB & Partido Republicano Brasileiro & 25.8 .2005 & http://www.prb10.org.br/ \\
\hline 26 & PSOL & $\begin{array}{l}\text { Partido Socialismo e } \\
\text { Liberdade }\end{array}$ & 15.9.2005 & http://www.psol50.org.br/ \\
\hline 27 & PR & Partido da República & 19.12 .2006 & http://www.partidodarepublica.org.br/ \\
\hline 28 & PSD & Partido Social Democrático & 27.9 .2011 & http://www.psd.org.br/ \\
\hline 29 & PPL & Partido Pátria Livre & 4.10 .2011 & http://partidopatrialivre.org.br/ \\
\hline 30 & PEN & Partido Ecológico Nacional & 19.6 .2012 & http://www.pen51.org.br/ \\
\hline 31 & PROS & $\begin{array}{l}\text { Partido Republicano da } \\
\text { Ordem Nacional }\end{array}$ & 24.9.2013 & http://http//www.pros.org.br/ \\
\hline 32 & SDD & Solidariedade & 24.9 .2013 & http://www.solidariedade.org.br/ \\
\hline
\end{tabular}

Fonte: Tribunal Superior Eleitoral. 
18 | Antonio Teixeira de Barros

\section{Estratégias dos websites dos partidos para conexão com a juventude}

Conforme ressalta Manin (2013), os partidos escolhem quais segmentos de público disponíveis eles querem atingir. Em outros termos, cada legenda constrói seu "público-alvo" em busca de apoio eleitoral. Para o autor, depois de avaliar os interesses específicos de cada segmento eleitoral, os líderes partidários precisam escolher quais seriam mais adequados, de acordo com tradição, restriçôes, histórico e reputação da legenda (MANIN, 2013, p. 120). De certa forma, Manin aponta para a realidade partidária, algo que outros pesquisadores já perceberam no mercado informativo: a segmentação dos públicos (WOLTON, 2006).

Para atingir seus públicos, os partidos adotam a estratégia de advocacy, que consiste, basicamente, na representação específica das demandas, interesses e causas de certos segmentos sociais que constroem uma identidade própria. É importante ressaltar que a advocacy é considerada uma modalidade de representação política (AVRITZER, 2007) ${ }^{4}$. Um dos aspectos mais relevantes para o caso em estudo é a análise do autor acerca de como os próprios partidos e representantes políticos podem exercer um tipo de representaçáo que também leva em conta dimensóes de advocacy. Trata-se de situaçóes em que a representaçáo abraça alguma forma de ativismo e incorpora em seu discurso a defesa, o patrocínio e o apoio de causas coletivas, em sintonia com a militância.

Apenas quatro dos 32 partidos não utilizam estratégias específicas de relação com a juventude. Trata-se de partidos de pequeno porte: PCdoB, PRP, PSOL e PR (Tabela 1). As quatro siglas apresentam websites com desenho muito similar, que exercem mais a função de mural informativo ou de outdoor para divulgar notícias, arregimentar militantes e oferecer um canal de contato, o e-mail institucional (CASTELLS, 2003). No caso da coincidência entre os 28 que recorrem à estratégia em exame, a explicação mais plausível é a necessidade dos partidos eleitorais de massa de dirigirem suas mensagens a públicos específicos, em vez de se dirigirem à totalidade dos cidadáos ou mesmo, no caso da esquerda, aos trabalhadores de forma geral. Também não é possível deixar de notar que a própria concorrência entre as legendas pode ser um fator de estímulo a formas de captação da atenção juvenil.

\footnotetext{
${ }^{4}$ Para o autor, existem três tipos de representação: a eleitoral, no qual a autorizaçáo se dá por meio do voto; a advocacia, que pressupóe a identificação do representante com a condição (social, econômica, cultural, etc.) do representado; e a representação da sociedade civil, em que a autorização dos atores com experiência no tema é condição essencial para sua escolha (AVRITZER, 2007, p. 458).
} 
Tabela 1 - Estratégias dos partidos quanto à relação com a juventude pelos websistes ${ }^{5}$

\begin{tabular}{|c|c|c|c|c|c|}
\hline & Partidos & $\begin{array}{c}\text { Núcleos de } \\
\text { juventude }\end{array}$ & $\begin{array}{c}\text { Educaçáo } \\
\text { política jovem }\end{array}$ & Mídias sociais & $\begin{array}{l}\text { Índice de relaçáo } \\
\text { com a juventude }\end{array}$ \\
\hline 1 & PMDB & 1 & 1 & 1 & 1,00 \\
\hline 2 & PTB & 1 & 1 & 0 & 0,66 \\
\hline 3 & PDT & 1 & 1 & 1 & 1,00 \\
\hline 4 & PT & 1 & 1 & 1 & 1,00 \\
\hline 5 & DEM & 1 & 1 & 1 & 1,00 \\
\hline 6 & PSB & 1 & 1 & 1 & 1,00 \\
\hline 7 & PSDB & 1 & 1 & 1 & 1,00 \\
\hline 8 & PTC & 1 & 1 & 0 & 0,66 \\
\hline 9 & PSC & 1 & 1 & 1 & 1,00 \\
\hline 10 & PMN & 1 & 1 & 1 & 1,00 \\
\hline 11 & PPS & 1 & 1 & 0 & 0,66 \\
\hline 12 & PV & 1 & 0 & 1 & 0,66 \\
\hline 13 & PTdoB & 1 & 1 & 1 & 1,00 \\
\hline 14 & PP & 1 & 0 & 1 & 0,66 \\
\hline 15 & PSTU & 1 & 1 & 1 & 1,00 \\
\hline 16 & PCB & 1 & 1 & 1 & 1,00 \\
\hline 17 & PRTB & 1 & 1 & 1 & 1,00 \\
\hline 18 & PHS & 1 & 1 & 1 & 1,00 \\
\hline 19 & PSDC & 1 & 1 & 1 & 1,00 \\
\hline 20 & $\mathrm{PCO}$ & 1 & 1 & 1 & 1,00 \\
\hline 21 & PTN & 1 & 1 & 1 & 1,00 \\
\hline 22 & PSL & 1 & 1 & 1 & 1,00 \\
\hline 23 & PRB & 1 & 1 & 1 & 1,00 \\
\hline 24 & PSD & 1 & 1 & 1 & 1,00 \\
\hline 25 & PPL & 1 & 0 & 1 & 0,66 \\
\hline 26 & PEN & 1 & 0 & 1 & 0,66 \\
\hline 27 & PROS & 1 & 1 & 1 & 1,00 \\
\hline 28 & SDD & 1 & 0 & 1 & 0,66 \\
\hline \multicolumn{2}{|r|}{ TOTAIS } & $28(87.5 \%)$ & $25(78,12 \%)$ & $28(87.5 \%)$ & \\
\hline
\end{tabular}

Fonte: Elaboraçáo do autor.

${ }^{5}$ É oportuno registrar que levantamento realizado no início de 2014 mostra que $75 \%$ dos partidos (27 de 32) apresentavam núcleos jovens em seus websites, o que significa que aumentou a adesão a essa estratégia durante a campanha eleitoral, oito meses depois do levantamento de Rodrigues, Barros e Bernardes (2014). Dois partidos criaram núcleos para jovens durante a campanha eleitoral: PSD e PPL. 
A tabela acima mostra um relativo investimento dos partidos em estratégias combinadas de relaçáo com o eleitorado jovem. Das 32 legendas, 28 (87.5\%) apresentam núcleos de juventude em seus websites e meios de interação pelas redes sociais online, enquanto $25(78,12 \%)$ oferecem cursos de educação política juvenil pela Internet. Quanto ao índice geral de relação, 20 agremiaçôes atingem a pontuação máxima $(1,00)$, enquanto nove ficaram em segundo lugar, com 0,66. A menor pontuação aferida ficou com apenas três legendas de pequeno porte $(0,33)$. $\mathrm{O}$ investimento na relação com a juventude se explica, em parte, porque se trata de um segmento expressivo do eleitorado, com 17,64\%, ou seja, 24,8 milhóes, conforme dados das eleiçóes de $2012^{6}$.

Com o propósito de situar o grau de relevância das estratégias de conexão dos partidos com o eleitorado juvenil, apresentamos um quadro comparativo com as formas de relação das siglas com demais segmentos eleitorais. Como mostra a Tabela 2, a juventude figura em primeiro lugar, com adesão de 28 partidos (87,5\%), seguido do eleitorado feminino (27 legendas) e os sindicatos (seis partidos).

Tabela 2 - A Juventude e os demais núcleos de advocacy dos partidos

\begin{tabular}{c|c|c|c}
\hline & Núcleos & $\mathbf{N}$ & $\%$ \\
\hline 1 & Juventude & 28 & 87,5 \\
\hline 2 & Mulheres & 27 & 84,4 \\
\hline 3 & Sindical & 06 & 18,6 \\
\hline 4 & Negro/Afro & 04 & 12,5 \\
\hline 5 & Movimentos populares / sociais & 04 & 12,5 \\
\hline 6 & Ambiente & 03 & 9,30 \\
\hline 7 & Cultura & 03 & 9,30 \\
\hline 8 & Aposentados e Pensionistas & 02 & 6,20 \\
\hline 9 & Indígenas & 01 & 3,10 \\
\hline
\end{tabular}

Fonte: Elaboração do autor.

Certamente, o foco na juventude constitui uma estratégia das legendas para arregimentar eleitores, em um contexto eleitoral caracterizado pela erosão das fidelidades partidárias e o aumento de eleitores flutuantes ou desvinculados (MANIN, 2013), o que vai ao encontro do potencial individual e coletivo proporcionado principalmente pelas mídias sociais. Tal cenário, conforme o mesmo autor, "reforçou a necessidade de dinamismo na mobilização de eleitores" (MANIN, 2013, p. 120). É certo que cada partido "retém uma base nuclear de eleitores fieis"; porém, à medida

\footnotetext{
${ }^{6}$ Informaçóes em: http://www.tse.jus.br/eleicoes/estatisticas/estatisticas-eleicoes-2012.
} 
que esse núcleo encolhe, cada legenda "precisa buscar o apoio de eleitores em outro lugar", atuando de forma proativa, a fim de tentar ampliar sua base eleitoral. Para isso, servem-se de dados de pesquisas de opinião, grupos focais e outros instrumentos de sondagem e monitoramento da opiniáo dos eleitores. Em suma, "os partidos raciocinam em termos de grupos de eleitores (como jovens, máes que trabalham, e assim por diante) e não em termos de eleitores individuais" (MANIN, 2013, p. 120).

\section{Estratégias de informação digital para a juventude}

Um mapeamento dos conteúdos publicados pelos núcleos de juventude dos websites dos 28 partidos que adotam essa estratégia (Tabela 3), mostra um predomínio de divulgação de informaçóes relacionadas a eventos políticos para o público jovem $(64,7 \%)$, seguida de notícias da agenda sociopolítica e cultural da juventude (46,5\%), como educação, cultura, esportes e lazer. São duas estratégias que usam a mesma lógica de conexão informacional e política. Do ponto de vista informativo, ambas reproduzem conteúdos divulgados em outros suportes e veículos, com o objetivo de atrair a atençáo dos jovens para temas com os quais existe notória afinidade, além de agenciá-los para a participação em eventos. Do ponto de vista político, ambas as estratégias fortalecem o poder de controle dessa agenda pelos partidos, que buscam agenciar o eleitorado jovem para alguns pontos focais em termos de informaçáo política e para o engajamento dos jovens em eventos igualmente de interesse das legendas. A divulgação da agenda de eventos políticos para juventude funciona como um chamamento ou até mesmo uma convocação do eleitorado jovem e dos filiados para o comparecimento a tais atividades.

Tabela 3 - Dados sobre o núcleo jovem no website dos partidos

\begin{tabular}{c|c|c|c|c|c|c|c|c}
\hline & Partidos & Executiva & Eventos & Notícias & Opiniáo & Enquetes & Contato & Índice \\
\hline 1 & PMDB & 1 & 1 & 0 & 0 & 0 & 1 & 0,428 \\
\hline 2 & PTB & 0 & 1 & 1 & 0 & 0 & 0 & 0,285 \\
\hline 3 & PDT & 0 & 1 & 0 & 0 & 0 & 1 & 0,285 \\
\hline 4 & PT & 0 & 1 & 0 & 0 & 0 & 1 & 0,285 \\
\hline 5 & DEM & 0 & 0 & 1 & 1 & 1 & 0 & 0,428 \\
\hline 6 & PSB & 0 & 1 & 0 & 0 & 0 & 1 & 0,285 \\
\hline 7 & PSDB & 0 & 0 & 0 & 1 & 0 & 1 & 0,285 \\
\hline 8 & PTC & 0 & 0 & 1 & 0 & 0 & 0 & 0,142 \\
\hline 9 & PSC & 0 & 0 & 1 & 1 & 1 & 0 & 0,428 \\
\hline 10 & PMN & 0 & 1 & 0 & 0 & 0 & 0 & 0,142 \\
\hline 11 & PPS & 0 & 1 & 0 & 1 & 1 & 0 & 0,428 \\
\hline
\end{tabular}




\begin{tabular}{l|c|c|c|c|c|c|c|c}
\hline 12 & PV & \multicolumn{6}{|c}{ Acesso ao núcleo jovem do website restrito a filiados cadastrados } & - \\
\hline 13 & PTdoB & 0 & 0 & 0 & 0 & 0 & 0 & 0,142 \\
\hline 14 & PP & 0 & 1 & 1 & 0 & 0 & 0 & 0,285 \\
\hline 15 & PSTU & 0 & 0 & 0 & 1 & 1 & 1 & 0,428 \\
\hline 16 & PCB & 0 & 1 & 1 & 1 & 0 & 0 & 0,571 \\
\hline 17 & PRTB & 0 & 0 & 1 & 0 & 0 & 1 & 0,285 \\
\hline 18 & PHS & 0 & 0 & 0 & 1 & 0 & 0 & 0,142 \\
\hline 19 & PSDC & 0 & 1 & 0 & 0 & 0 & 1 & 0,285 \\
\hline 20 & PCO & 0 & 1 & 0 & 0 & 0 & 0 & 0,142 \\
\hline 21 & PTN & 0 & 1 & 0 & 0 & 0 & 0 & 0,142 \\
\hline 22 & PSL & 0 & 1 & 0 & 0 & 0 & 0 & 0,142 \\
\hline 23 & PRB & 0 & 1 & 1 & 0 & 0 & 1 & 0,428 \\
\hline 24 & PSD & 0 & 1 & 1 & 0 & 0 & 0 & 0,285 \\
\hline 25 & PPL & 0 & 1 & 1 & 0 & 0 & 0 & 0,285 \\
\hline 26 & PEN & 0 & 1 & 1 & 0 & 1 & 0 & 0,428 \\
\hline 27 & PROS & 0 & 0 & 1 & 0 & 0 & 0 & 0,142 \\
\hline 28 & SDD & 0 & 1 & 1 & 0 & 0 & 0 & 0,285 \\
\hline \multicolumn{2}{l}{ TOTAIS } & 1 & 18 & 13 & 7 & 5 & 9 & - \\
\hline
\end{tabular}

Fonte: Elaboraçáo do autor, com dados dos websites dos partidos.

Em terceiro lugar, destacam-se as formas usadas pelas agremiaçôes para estimular os jovens a entrarem em contato com os partidos por meio dos canais oferecidos pelos websites. Entre esses canais, destacam-se: e-mail institucional do núcleo jovem, redes sociais e a assinatura de boletim eletrônico (newsletter) com temas relacionados à agenda jovem (32,10\%). A divulgação de entrevistas e de artigos de opinião de lideranças jovens figura em quarto lugar (25\%). Trata-se de uma forma de acionar os próprios jovens para atrair e captar a atenção de outros jovens.

Em quinto lugar, estão as enquetes $(17,85 \%)$, que consistem na captação de tendências de opiniáo sobre temas de abrangência nacional. Contudo, o levantamento não registra abordagem te temas típicos da agenda jovem, mas a inclusão de enquetes que estão no website das legendas e que exploram temas econômicos, políticos e ecológicos em termos gerais. Por fim, estão as informaçôes sobre a executiva nacional da juventude dos partidos (3,5\%), representado por um partido de grande porte, o PMDB, que aparece como o único a contar com uma estrutura de organizaçáo voltada para a juventude. 


\section{Estratégias de educação politica online para a juventude}

Em relação ao tema da educação política juvenil, a Tabela 1 mostra que 25 partidos adotam projetos e estratégias permanentes nessa área, o que corresponde a $75,12 \%$ do total de siglas. Trata-se de uma categoria com conteúdos voltados especificamente para os jovens eleitores e inclui informaçóes sobre políticas públicas para a juventude, modos de participação dos jovens na política e como os partidos atuam na promoção da cidadania juvenil. A prevalência dessa estratégia mostra que os partidos estão decididos a investir na formação e na renovação de seus quadros e estimular a participaçáo e o ingresso da juventude na política. As ferramentas de EAD (educação à distância) são usadas por todas as agremiaçóes contempladas, com a oferta de cursos online, com tutoria e emissão de certificado por uma entidade conveniada. Os websites oferecem ainda estudos políticos e econômicos, videoteca virtual para download, com documentários e vídeos políticos, além de conteúdos sobre educação para a sociedade multicultural, educação ambiental, história do pensamento político, teorias da democracia e outros temas com potencial para captar a atenção da juventude.

É oportuno ressaltar que a Lei dos Partidos Políticos (Lei Federal 9.096/1995) estabelece que as legendas devem aplicar 20\% dos recursos oriundos do Fundo Partidário para atividades de educação política, além de manutenção de institutos de pesquisa e doutrinação. As iniciativas, portanto, são estimuladas pela própria legislação em vigor. Outro aspecto relevante a ser considerado é o desafio dos partidos frente à cultura política de desconfiança popular, em especial no segmento juvenil. Afinal, como legitimar tais conteúdos educativos em um cenário de ceticismo e falta de confiança da população jovem? (DANTAS, 2014).

\section{Estratégias de contato e interação com a juventude pelos websites}

Apesar de não se tratar de estratégias exclusivas para relação com a juventude, é consensual que o uso de ferramentas tecnológicas é um atrativo para o público juvenil. Conforme aponta a nona edição da pesquisa TIC Domicílios 2013, realizada pelo Centro de Estudos sobre as Tecnologias da Informação e da Comunicação (CETIC) ${ }^{7}$, os jovens continuam a ser os mais conectados: $75 \%$, entre os brasileiros de 10 a 15 anos; 77\%, entre os de 16 a 24; e 66\%, entre os de 25 a 34 anos. Em suma, os jovens são "nativos digitais" e se relacionam com ferramentas tecnológicas com

\footnotetext{
${ }^{7}$ Disponível em: http://cetic.br/pesquisa/domicilios/indicadores.
} 
muita habilidade e desenvoltura. Certamente, os partidos consideram esse fator ao traçar suas estratégias de informação digital. Faltam dados sobre a relação específica dos partidos com a juventude, como aponta Amaral (2013). Entretanto, um mapeamento geral das estratégias de uso da Internet revela um desenho geral dessa relação.

Em uma primeira avaliação geral das estratégias de contato e interação pelos sites dos partidos, percebe-se, na Tabela 4, que há um bom uso de recursos tecnológicos para deixar a informação mais interessante, acessível e atualizada (vide os $100 \%$ que todos os partidos obtiveram em uso de recursos multimídia, como vídeos e áudios, e no investimento em atualização de conteúdo). Percebe-se que todas as siglas também desejam ter um ponto de contato e/ou acesso com o cidadão jovem, já que a totalidade possui algum meio de contato como e-mail, por exemplo. O percentual já cai muito (para 21,9\%) quando a questáo é o uso de ferramentas de sondagem, como enquetes, ou seja, há, ainda que baixo, o interesse em ter um termômetro sobre a opinião da juventude em relação a temas considerados importantes pelos partidos que adotam o instrumento. Entretanto, o percentual cai para zero quando são considerados os recursos para debates, indicando não haver interesse em um debate mais efetivo (BRAGA, FRANÇA e NICOLÁS, 2009).

Apesar disso, 87,5\% possuem alguma mídia social, que são potencialmente interativas ${ }^{8}$. O indício é de que os partidos ainda usem as mídias sociais, tal como a maioria das instituiçóes políticas (NORRIS, 2001), para visibilidade e publicidade de seus atos, assim como nos sites. Ou seja, os dispositivos são diferentes, mas a lógica usada parece ser a mesma de ferramentas mais tradicionais da Internet, como os websites oficiais.

Infere-se, pois, que há uma clara percepção dos partidos de que a juventude está presente nessas mídias e de que é preciso participar delas, ainda que de forma sistemática. Novamente, contudo, pode estar operando aqui sob a perspectiva competitiva entre as siglas, isto é, a necessidade de adotar todas as ferramentas já usadas pelos demais competidores eleitorais.

\footnotetext{
${ }^{8}$ Foram consideradas: Youtube; Twitter; Facebook; Orkut; Instagram; soundcloud; Google +; Flickr; Linkedin.
} 
Tabela 4 - Recursos de multimídia, interação e debate nos websites dos partidos

\begin{tabular}{c|c|c}
\hline Ferramentas utilizadas & N & \% \\
\hline Recursos de multimídia & 32 & 100 \\
\hline Meios de contato & 32 & 100 \\
\hline Ferramentas de interação & 28 & 87,5 \\
\hline Instrumentos de sondagem e percepçáo de opinião pública & 07 & 21,9 \\
\hline Recursos de debate & 0 & 0 \\
\hline Atualização semanal & 32 & 100 \\
\hline
\end{tabular}

Fonte: Elaboração do autor.

Entre as mídias sociais, a mais utilizada pelas legendas é o Twitter, que está presente em 96,43\% (27) dos websites. Em seguida, vêm o Facebook, com 89,23\% (25); Youtube, com 60,71\% (17); e Flickr, com 17,86\% (Tabela 5). As demais têm todas menos de $16 \%$. Corroborando as análises acima, vemos que um grande número de partidos participa de alguma rede social digital, sobretudo das mais populares, como Twitter e Facebook. O Twitter se caracteriza pela rapidez e facilidade de propagaçáo de opiniôes, principalmente não pessoais, talvez daí sua leve preponderância sobre o Facebook e grande diferença em relação às outras. O uso de redes mais atuais, focadas em imagem e som, como Flickr, Instagram e Soundcloud, ainda não parece fazer parte das estratégias dos partidos.

Cabe salientar que o Facebook é a rede social preferida pelos jovens brasileiros, com 73,5\% de adesão, conforme estudo do Experian Marketin Service (2013). Em segundo lugar está o Youtube, com 16,34\% da preferência juvenil. O Twitter figura em sétimo lugar, com $0,70 \%{ }^{9}$.

\footnotetext{
9 Ranking completo em: http://www.emarketer.com/Article/Badoo-Becomes-No-3-Social-NetworkBrazil/1010436.
} 
Tabela 5 - Uso de mídias sociais como estratégia de conexão com a juventude

\begin{tabular}{|c|c|c|c|c|c|c|c|c|c|c|c|}
\hline & Partido & Youtube & Twitter & Facebook & Orkut & Instagram & Soundcloud & Google+ & Flickr & Linkedin & $\begin{array}{l}\text { Indice } \\
\text { Geral }\end{array}$ \\
\hline 1 & PMDB & 1 & 1 & 1 & 0 & 0 & 0 & 0 & 1 & 0 & 0,44 \\
\hline 2 & PTB & 0 & 0 & 0 & 0 & 0 & 0 & 0 & 0 & 0 & 0,00 \\
\hline 3 & PDT & 0 & 1 & 1 & 0 & 0 & 0 & 0 & 0 & 1 & 0,33 \\
\hline 4 & PT & 1 & 1 & 1 & 1 & 0 & 1 & 0 & 0 & 0 & 0,55 \\
\hline 5 & DEM & 0 & 1 & 1 & 0 & 0 & 0 & 1 & 1 & 0 & 0,44 \\
\hline 6 & PCdoB & 0 & 1 & 0 & 0 & 0 & 0 & 0 & 0 & 0 & 0,11 \\
\hline 7 & PSB & 0 & 1 & 1 & 0 & 0 & 0 & 0 & 0 & 0 & 0,22 \\
\hline 8 & PSDB & 1 & 1 & 1 & 0 & 1 & 0 & 1 & 0 & 0 & 0,55 \\
\hline 9 & PTC & 0 & 0 & 0 & 0 & 0 & 0 & 0 & 0 & 0 & 0,00 \\
\hline 10 & PSC & 1 & 1 & 1 & 0 & 0 & 0 & 0 & 1 & 0 & 0,44 \\
\hline 11 & PMN & 1 & 1 & 1 & 1 & 0 & 0 & 0 & 0 & 0 & 0,44 \\
\hline 12 & PRP & 0 & 0 & 0 & 0 & 0 & 0 & 0 & 0 & 0 & 0,00 \\
\hline 13 & PPS & 0 & 0 & 0 & 0 & 0 & 0 & 0 & 0 & 0 & 0,00 \\
\hline 14 & PV & 1 & 1 & 1 & 0 & 0 & 0 & 0 & 1 & 0 & 0,44 \\
\hline 15 & PTdoB & 0 & 1 & 1 & 0 & 0 & 0 & 0 & 1 & 0 & 0,33 \\
\hline 16 & $\mathrm{PP}$ & 1 & 1 & 0 & 0 & 0 & 0 & 0 & 1 & 0 & 0,33 \\
\hline 17 & PSTU & 1 & 1 & 1 & 0 & 0 & 0 & 0 & 0 & 0 & 0,33 \\
\hline 18 & PCB & 0 & 1 & 1 & 0 & 0 & 0 & 0 & 0 & 0 & 0,22 \\
\hline 19 & PRTB & 0 & 0 & 1 & 0 & 0 & 0 & 1 & 0 & 0 & 0,22 \\
\hline 20 & PHS & 1 & 1 & 1 & 0 & 0 & 0 & 0 & 1 & 0 & 0,44 \\
\hline 21 & PSDC & 1 & 1 & 1 & 0 & 0 & 0 & 0 & 0 & 0 & 0,33 \\
\hline 22 & PCO & 0 & 1 & 1 & 1 & 0 & 0 & 0 & 0 & 0 & 0,33 \\
\hline 23 & PTN & 1 & 1 & 1 & 0 & 0 & 0 & 0 & 0 & 0 & 0,33 \\
\hline 24 & PSL & 0 & 1 & 1 & 0 & 0 & 0 & 0 & 0 & 0 & 0,22 \\
\hline 25 & PRB & 1 & 1 & 1 & 0 & 0 & 0 & 0 & 0 & 0 & 0,33 \\
\hline 26 & PSOL & 0 & 1 & 1 & 0 & 0 & 0 & 0 & 0 & 0 & 0,22 \\
\hline 27 & PR & 1 & 1 & 1 & 0 & 0 & 0 & 0 & 0 & 0 & 0,33 \\
\hline 28 & PSD & 1 & 1 & 1 & 0 & 0 & 0 & 0 & 1 & 0 & 0,44 \\
\hline 29 & PPL & 0 & 1 & 1 & 0 & 0 & 0 & 1 & 0 & 0 & 0,33 \\
\hline 30 & PEN & 1 & 1 & 1 & 0 & 0 & 0 & 0 & 1 & 0 & 0,44 \\
\hline 31 & PROS & 1 & 1 & 1 & 0 & 0 & 0 & 1 & 0 & 0 & 0,44 \\
\hline \multirow[t]{2}{*}{32} & SDD & 1 & 1 & 1 & 0 & 0 & 0 & 0 & 1 & 0 & 0,44 \\
\hline & $\begin{array}{c}\text { TOTAL } \\
\mathrm{N}=28\end{array}$ & $\begin{array}{c}17 \\
60,7 \% \\
\end{array}$ & $\begin{array}{c}27 \\
96,4 \% \\
\end{array}$ & $\begin{array}{c}25 \\
89,3 \% \\
\end{array}$ & $\begin{array}{c}3 \\
10,7)\end{array}$ & $\begin{array}{c}1 \\
3,5 \%\end{array}$ & $\begin{array}{c}1 \\
3,5 \%\end{array}$ & $\begin{array}{c}5 \\
17,9 \%\end{array}$ & $\begin{array}{c}10 \\
35,7 \%\end{array}$ & $\begin{array}{c}1 \\
3,5 \%\end{array}$ & \\
\hline
\end{tabular}

Fonte: Elaboração do autor.

Considerando um índice quantitativo de participação em redes sociais, observamos que o PT e o PSDB são as que mais investem em redes sociais diferentes, com o índice de 0,55 (cada um deles está em 5 redes diferentes). Em segundo lugar, estão dez legendas, com o mesmo índice $(0,44)$ : PMDB, DEM, PSC, PV, PHS, $\mathrm{PSD}, \mathrm{PEN}, \mathrm{PROS}$ e SDD. Os quatro partidos que não possuem rede alguma são: PTB, PTC, PRP e PPS. Entretanto, não podemos avaliar se isso reflete alguma posiçáo negativa em propiciar um diálogo com a juventude. 


\section{Conclusões}

O estudo mostra que a juventude é o foco das estratégias de informação e relação dos websites dos partidos políticos brasileiros. Das 32 legendas, 28 (87.5\%) apresentam núcleos de juventude em seus websites e meios de interação pelas redes sociais online, enquanto $25(78,12 \%)$ oferecem cursos de educação política juvenil pela Internet. Esse elevado investimento na relação com a juventude se explica, em parte, porque se trata de um segmento expressivo do eleitorado brasileiro, com 17,64\%, ou seja, 24,8 milhões, conforme dados das eleiçôes de 2012. Entretanto, é necessário considerar ainda o argumento de que os jovens se tornaram sujeitos sociais de grande peso nas decisóes de voto familiar, uma vez que estudos mostram a força persuasiva dos mais jovens em relação aos membros mais velhos das famílias. Isso se explica exatamente pelo maior capital informacional da juventude em relação a seus pais, tios e avós, além da capacidade de uso das novas tecnologias de informaçáo e de interação digital (RODRIGUES, 2014).

As estratégias dos websites dos partidos para a relaçáo com o eleitorado jovem têm como eixo os mecanismos para aumentar a visibilidade das propostas dos partidos, mesmo no caso do uso das redes sociais digitais e da educação política online. Portanto, ainda que haja disponibilização, assim como há com as redes sociais, o potencial interativo das ferramentas digitais parece não ser plenamente aproveitado. Desta forma, pode-se sugerir, como conclui Blanchard (2006, p. 12), que "a pesquisa e o desenvolvimento de interaçôes com os cidadãos numa perspectiva deliberativa não são, com e nos websites, a prioridade dos partidos". A ênfase na visibilidade reforça o pragmatismo da atuação partidária (BAQUERO, 2000; NICOLAU, 2010) em detrimento da via discursiva dialógica (CASTELLS, 2003).

De maneira geral, a análise revela que as estratégias de educação política estão associadas à defesa da grandeza cívica dos partidos (BOLTANSKI, 2000) ${ }^{10}$, com conteúdos voltados para destacar os feitos das legendas, o legado histórico, cívico e político. Assim, pretende-se fortalecer a identidade partidária, ampliar os quadros dirigentes e conquistar novos militantes e simpatizantes. $\mathrm{O}$ objetivo parece ser o de fazer os jovens cidadãos conhecerem e reconhecerem a identidade partidária, por meio da sugestáo de uma imagem mais social e moderna, o que tem a ver também

\footnotetext{
${ }^{10}$ Segundo essa perspectiva, o partido atua em nome de um coletivo, cuja vontade geral ele representa. A grandeza cívica refere-se à defesa de interesses públicos, de forma republicana, sem contaminação por motivaçóes personalistas ou de grupos oligárquicos.
} 
com visibilidade. Trata-se de algo similar ao modo pelo qual se formam as almas (CARVALHO, 1990), cujo princípio operatório se dá pela atuação dos símbolos e da doutrina dos partidos.

O levantamento mostra, ainda, que existe uma configuração comum dos websites estudados, o que se explica provavelmente pelo uso estratégico das ferramentas da web e pela própria lógica da Internet (CASTELLS, 2003), além da concorrência entre as legendas, conforme já foi abordado acima. Tal configuração, contudo, ao mesmo tempo que facilita as estratégias de visibilidade, advocacy e interação, por exemplo, também pode acarretar perdas para a identidade dos partidos; afinal, a lógica que rege a organização é marcada pela distinção, ou seja, cada legenda tenta apresentar-se à sociedade a partir de suas particularidades e não das semelhanças com as demais.

- Antonio Teixeira de Barros é Doutor em Sociologia. Professor e Pesquisador do Programa de Pós-Graduação do Centro de Formação Política da Câmara dos Deputados (CEFOR). E-mail: antonibarros@gmail.com.

\section{Referências}

ALBUQUERQUE, Afonso de; MARTINS, Adriane Figueirola. Apontamentos para um modelo de análise de partidos na web. Trabalho apresentado ao grupo de trabalho "Comunicação e política", do XIX Encontro da Compós, na PUC-RJ, junho de 2010. Disponível em http://compos.com.pucrio.br/media/gt3_afonso_de_albuquerque_adriana_figueirola_martins.pdf. Acessado em 18 jun. 2014.

AMARAL, Oswaldo E. O que sabemos sobre a organização dos partidos políticos: uma avaliação de 100 anos de literatura. Debates, Porto Alegre, v. 7, n. 2, maio/ago., 2013, p. 11-32.

AVRITZER, Leonardo. Sociedade civil, instituiçôes participativas e representação: da autorização à legitimidade da ação. Dados, v. 50, n. 3, 2007, p. 443-464.

BAPTISTA, Érica Anita et al. Jovens eleitores e novas tecnologias: percepções da política e participação. Revista do Legislativo. Belo Horizonte, v. 5, n.1, jan., 2013, p.124-132.

BAQUERO, M arcelo. A vulnerabilidade dos partidos politicos e a crise da democracia na América Latina. Porto Alegre: Ed. Universidade/UFRGS, 2000.

BAUMAN, Zygmunt. Em busca da politica. Rio de Janeiro: Zahar, 2000.

BLANCHARD, Gersend. O uso da Internet a serviço da comunicação do partido. Líbero, v. 9, n. 18, p. 9-17, dez 2006. 
BOLTANSKI, Luc. El amor e La justicia como competências. Buenos Aires: Amorrortu, 2000.

BOURDIEU, Pierre. O poder simbólico. Lisboa, Portugal: Difel, 1989.

BRAGA, Sérgio; FRANÇA, Andressa Silvério Terra; NICOLÁS, Maria Alejandra. Os partidos políticos brasileiros e a Internet. Rev. Sociologia e Política, v. 17, n. 34, p. 183-208, out, 2009.

CARREIRÃO, Yane; KINZO, Maria D.G. Partidos políticos, preferência partidária e decisão eleitoral no Brasil (1989/2002). Dados, vol. 47, n. 1, 2004, p. 131-168,.

CARVALHO, José Murilo. A formação das almas: o imaginário da República no Brasil. São Paulo: Companhia das Letras, 1990.

CASTELLS, Manuel. A galáxia da Internet. Rio de Janeiro: Zahar, 2003.

CASTRO, Lucia Rabello de. Juventude e socializaçáo política. Psicologia: Teoria e Pesquisa, v. 25, n. 4, 2009, p. 479-487.

DALTON, Russel; WATTENBERG, Martin (org.). Parties without Partisans: Political Change in Advanced Industrial Democracies, Oxford, Oxford University Press, 2000.

DANTAS, Humberto. Partidos podem educar? Estadão.com.br, 03 de abr. 2014. Em:

http://www.estadao.com.br/noticias/nacional,analise-partidos-podem-educar,1126122,0.htm. Acesso em 09 de abr. 2014.

DAYRELL, Juarez; MOREIRA, M. Ignez Costa; STENGEL, Márcia. Juventudes contemporâneas: um mosaico de possibilidades. Belo Horizonte: Ed. PUC Minas, 2011.

GOHN, Maria da Glória. Os jovens e as praças dos indignados: territórios de cidadania. Revista Brasileira de Sociologia, v. 1, n. 2, p. 205-221, jul/dez 2013.

HARVEY, David. Condição pós-moderna. São Paulo: Loyola, 1992.

LESTON-BANDEIRA, Cristina. Studying the relationship between Parliament and citizens. The Journal of Legislative Studies, v.18, n. 3-4, Sep-Dec. 2012, p. 265-274.

LIPOVETSKY, Gilles. A era do vazio. Lisboa: Ediçóes 70, 2013.

MAINWARING, Scott. P. Sistemas Partidários em Novas Democracias: O Caso do Brasil. Rio de Janeiro. FVG, 2001.

MAYORGA, Cláudia; CASTRO, Lúcia. R.; PRADO, Marco Antonio M. (Orgs.). Juventude e a experiência da política no contemporâneo. Rio de Janeiro: Contra Capa Editora, 2012.

MALFITANO, Ana Paula Serrata. Juventudes e contemporaneidade: entre a autonomia e a tutela. Etnográfica, Lisboa, v. 15, n. 3, 2011, p. 523-542.

MANIN, Bernard. A democracia do público reconsiderada. Novos Estudos CEBRAP. São Paulo, n. 97, p. 115-127, 2013.

MENEGUELlO, Rachel. Partidos Conservadores no Brasil. Sáo Paulo. Paz e Terra, 2000.

MILBRATH, Lester.; GOEL, Madanlal. Political participation. Boston: University Press of America, 1977.

MOISES, JOSÉ ÁLVARO. A desconfiança nas instituições democráticas. Opinião Pública, v. 11, n. 1, p. 33-63, 2005.

NICOLAU, Jairo. Parties and democracy in Brazil, 1985-2006: moving toward cartelization. In Political Parties and Democracy: Volume I: The Americas, org. Key Lawson and Jorge Lanzaro. Praeger, 2010.

NORRIS, P ipa. Preaching to the converted? Pluralism, participartion and party websites. Party Politics, v. 9, n 1, p. 21-45, 2003. 
OKADO, Lucas Toshiaki Archangelo. Juventude e participação política no Brasil: efeitos geracionais ou de ciclos de vida?. Revista Espaço Acadêmico, v. 13, n. 147, 2013, p. 37-50.

PAIVA, Angela R. Juventude, Cidadania e a Cultura Cívica Possível. Trabalho apresentado no $34^{\circ}$. Encontro Anual da Anpocs. Anais... Caxambu, 25 a 29 de outubro de 2010.

PANEBIANCO, Angelo. Modelos de partido. Madrid: Alianza Editorial, 1990.

PEIRANO, Marisa. O dito e o feito. São Paulo: Relume-Dumará, 2011.

PEREIRA, Frederico Batista. A estabilidade e a efetividade da preferência partidária no Brasil. Revista Brasileira de Ciência Política. n. 13, p. 213-244, 2014.

REIS, Fábio Wanderley. Identidade política, desigualdade e partidos brasileiros. Novos estud. CEBRAP, n. 87, 2010, p. 61-75.

RIBEIRO, Eliane; LANES, Patrícia; CARRANO, Paulo. Diversidade de perfis caracteriza as juventudes brasileiras. Ibase, 2006. http://www.ibase.br/userimages/ibasenet_dv30_indicadores.pdf Acesso em 30 de jun. 2014.

RIBEIRO, Gustavo Lins. Cultura e politica no mundo contemporâneo. Brasília, EdUnB, 2000.

RODRIGUES, Alan. O que os jovens pensam sobre a política. IstoÉ, edição n. 2336, 29 agosto de 2014.

Disponível

em: http://www.istoe.com.br/reportagens/380009_O+QUE+OS+JOVENS+PENSAM+SOBRE+A+PO LITICA Consultado em 16/09/14.

RODRIGUES, Malena Rehbein.; BARROS, Antonio Teixeira; BERNARDES, Cristiane Brum. Palanques virtuais: o uso de websites pelos partidos políticos brasileiros. Texto apresentado no $38^{\circ}$. Encontro Anual da Anpocs, Águas de Líndóia (SP), set., 2014. Anais do 38 ${ }^{\circ}$. Encontro Anual da Anpocs.

RÖMMELE, Andrea. Political parties, party communication and new information and communication technologies. Party Politics, 2003, v. 9, n. 1, p. 7-20.

TELLES, Helcimara de S.; DIAS, Mariana. Condutas políticas, valores e voto dos eleitores jovens de Belo Horizonte. Revista do Legislativo. Belo Horizonte, n. 43, jan. 2010, p. 82-102.

URBINATI, Nadia. Crise e metamorfoses da democracia. Revista Brasileira de Ciências Sociais, São Paulo, v.28, n. 82, p. 5-16, 2013.

VEIGA, Luciana Fernandes. Os partidos brasileiros na perspectiva dos eleitores. Opiniáo Pública, Campinas, v. 13, n. 2, p. 340-365, 2007.

WEBER, Max. Economia e Sociedade, Comunidades políticas: natureza e conformidade à lei (legitimidade) das associações políticas Brasília: EdUnb, 1999, p. 155-186.

WOLTON, Dominique. Internet, e depois? Uma teoria crítica das novas mídias. São Paulo: Paulus, 2006.

ZITKOSKI, J. José; HAMMES, L. Jorge. Juventude, educação e cidadania: os desafios da participação social e política. Debates, Porto Alegre, v. 8, n. 2, p. 119-139, maio/ago, 2014.

Texto recebido em 12 de novembro de 2015 . Aprovado em 22 de julho de 2016. 